Konservasi Hayati, 16 (2): 71-76, Oktober (2020)

https://ejournal.unib.ac.id/index.php/hayati/

p-ISSN: 0216-9487

email:konservasihayati@unib.ac.id

e-ISSN: 2722-1113

\title{
MORFOMETRI KEPALA DAN WAJAH PADA MASYARAKAT SUKU BALI DI DESA SURO BALI KECAMATAN UJAN MAS KABUPATEN KEPAHIANG PROVINSI BENGKULU
}

\author{
Mesi Anggraini ${ }^{1}$, Choirul Muslim ${ }^{2 *}$, Santi Nurul Kamilah ${ }^{3}$ \\ 1,2,3 Jurusan Biologi, FMIPA, Universitas Bengkulu, Bengkulu \\ *Corresponding author: choirulmuslim@unib.ac.id
}

\begin{abstract}
Morphometry is a method of measurement, calculation, or assessment, in which the morphological characters can be described to understand the differentiation of various species and species variations. This study aims to determine the variation of head and face morphometry in Balinese tribes in Suro Bali Village, Ujan Mas District, Kepahiang Regency, Bengkulu Province. Data collection had been conducted in January 2020. The samples were taken with purposive sampling and then descriptively analyzed. The results showed that, of 76 respondents consisting of 33 males and 43 females, most males with medium head width category, long head category, long face category, narrow face category, brachycephalic head type and hyperleptoprosopic face type. On the other hand, females were with wide head category, medium head category, medium length and width face categories, hyperbrachycephalic head type and mesoprosopic face type.
\end{abstract}

Keywords: morphometry, Balinese, head type, face type, Kepahiang Bengkulu

\begin{abstract}
ABSTRAK
Ilmu morfometri merupakan salah satu metode pengukuran, perhitungan atau pemberian skor dimana karakter-karakter morfologi yang diukur dapat dideskripsikan guna mengetahui diferensiasi berbagai spesies dan variasi spesies. Penelitian ini bertujuan untuk mengatahui variasi morfometri tipe kepala dan wajah pada masyarakat suku Bali di Desa Suro Bali Kecamatan Ujan Mas Kabupaten Kepahiang Provinsi Bengkulu. Penelitian ini telah dilaksanakan pada bulan Januari 2020, dimana pengambilan sampel dilakukan secara purposive sampling dan dianalisis secara deskriptif. Hasil penelitian menunjukkan, dari 76 responden yang terdiri dari 33 orang laki-laki dan 43 orang perempuan, bahwa laki-laki paling banyak memiliki lebar kepala kategori sedang, panjang kepala kategori panjang, panjang wajah kategori panjang, lebar wajah kategori sempit, tipe kepala brachycephalic dan tipe wajah hyperleptoprosop. Sedangkan perempuan memiliki lebar kepala kategori lebar, panjang kepala kategori sedang, panjang wajah kategori sedang, lebar wajah kategori sedang, tipe kepala hyperbrachycephalic dan tipe wajah mesoprosop.
\end{abstract}

Kata kunci : morfometri, suku Bali, tipe kepala, tipe wajah, Kepahiang Bengkulu

\section{PENDAHULUAN}

Indonesia merupakan negara yang kaya akan keberagaman suku bangsa dan budaya, salah satunya adalah suku Bali. Berdasarkan asal usulnya suku Bali dapat dibedakan menjadi dua yaitu Bali Majapahit dan Bali Mula atau Bali Aga (Mantra, 1991). Menurut Darsana (1980) Bali Mula atau Bali Aga adalah suku bali yang mendiami daerah pegunungan sedangkan Bali Majapahit mendiami daerah dataran. Selain itu perbedaan lain dari keduanya yaitu pada penggunaan bahasa dan struktur masyarakat. Hal ini tampak dari pola kemasyarakatan Bali Dataran yang menganut sistem pelapisan yang dikenal dengan nama kasta atau wangsa.

Suku Bali mendiami Provinsi Bali dan diberbagai daerah Indonesia seperti Nusa Tenggara Barat, Sulawesi Tengah, Lampung, Bengkulu dan daerah penempatan 
transmigrasi asal Bali lainnya. Di Provinsi Bengkulu sendiri terdapat sebuah Desa yang bernama Suro Bali yang terletak di Kecamatan Ujan Mas Kabupaten Kepahiang. Desa Suro Bali berdiri pada tahun 1982 dengan luas wilayah 237 hektar dengan jumlah penduduk sebanyak 526 jiwa. Masyarakat Suro Bali umumnya merupakan petani palawija seperti cabai, buncis, terong, tomat dan sebagainya. Suro Bali juga merupakan desa yang multi-agama dimana masyarakatnya ada yang menganut agama Hindu, Budha, Islam, dan Kristen (Profil Desa Kepahiang, 2019).

Setiap suku yang ada di Indonesia mempunyai karakteristik atau ciri yang berbeda, termasuk karakter pada kepala dan wajah. More dkk. (2013) menyatakan bahwa kepala merupakan bagian superior tubuh dan menempel pada bagian batang leher yang mana tulang pembentuk kepala adalah cranium atau tulang tengkorak yang merupakan jembatan antara otak dan kepala. Sehingga cranium atau tulang tengkorak terbentuk menjadi dua bagian yaitu neurocranium dan viscerocranium. Neurocranium adalah tulang pelindung pada otak dan lapisan pembungkus otak. Sedangkan viscerocranium merupakan bagian cranium yang terdiri dari tulang-tulang pembentuk wajah yang berkembang dari mesenkim lengkung faring pada masa embrio.

Widyarini (2009) menyatakan bahwa wajah sangat bervariasi antara pria dan wanita. Variasi wajah manusia disebabkan adanya perbedaan informasi genetik dan pengaruh lingkungan. Variasi bentuk wajah terdapat pada tinggi wajah, lebar wajah, dahi, dagu, dan rahang. Karena cranium merupakan jembatan antara otak dan wajah, sehingga wajah tidak akan lebih luas dari cranium. Namun semakin luas cranium maka wajah akan semakin luas (Glinka, 1990)

Salah satu metode yang dapat dilakuakan untuk mengetahui kekerabatan suatu spesies tertentu, mengetahui diferensiasi dari berbagai spesies, mengetahui variasi spesies dan mengidentifikasikan suatu spesies yang melalui pengukuran, penghitungan atau pemberian skor yang karakter-karakternya dideskripsikan adalah morfometri (Bookstein, 1991)

Untuk mengetahui identitas suatu suku dengan mendeskripsikan bentuk dan ukuran tubuh manusia belum banyak dilakukan pada suku-suku yang ada di Indonesia. Sedangkan identifikasi terhadap seseorang melalui pendekatan unitunit anatomi tubuh sangat berguna dalam bidang penyidikan dan penelitian. Sehingga dengan pengukuran subyek hidup kita dapat memberikan ruang untuk mengklasifikasikan rasial dan kelompok etnik. Hal ini dikembangkan dengan cara menghitung keterkaitan beberapa titik pada tubuh manusia (Artaria et al, 2008)

Selain itu informasi mengenai morfometri wajah suku Bali masih sangat terbatas. Penelitian yang pernah dilakukan mengenai suku Bali yaitu mengenai variasi bentuk wajah dilakukan oleh Putra et al. (2017) dimana hasil dari penelitian tersebut diketahui bahwa rata-rata tipe wajah lakilaki di Desa Panglipuran berbentuk ellips sedangkan pada perempuan berbentuk bulat. Berdasarkan penelitian tersebut diduga adanya pengaruh variasi bentuk wajah terhadap lingkungan atau tempat tinggal.

Masyarakat suku Bali di Desa Suro Bali, Kecamatan Ujan Mas, Kabupaten Kepahiang, Provinsi Bengkulu telah hidup turun temurun di wilayah ini, sehingga menarik untuk mengetahui variasi morfologi wajahnya. Untuk itu, dilakukan penelitian ini untuk mengetahui aspek-aspek dan variasi morfologi wajah suku Bali di kawasan tersebut.

\section{METODE}

Pengambilan sampel dilakukan secara purposive pada suku Bali di Desa Suro Bali dengan syarat minimal dalam 3 generasi adalah keturunan asli dan berusia minimal 15 tahun. Sebelum pengambilan data, individu sampel (probandus) dipastikan mengisi formulir persetujuan atau kesediaan (informed concent). Kemudian setiap probandus diambil data pengukuran morfometri wajah dan kepalanya. Alat yang digunakan berupa caliper rentang, kamera, meteran/pita ukur, penggaris, kain polos dan 
alat tulis. Morfometri kepala yang diukur yaitu panjang dan lebar kepala guna menetukan tipe kepala probandus berdasarkan indeks cephalic. Sedangkan untuk morfometri wajah, bagian yang diukur adalah panjang wajah dan lebar bizygomatic guna menentukan tipe wajah pada probandus berdasarkan indeks facial. Selanjutnya dilakukan analisa data secara deskriptif. Rumus perhitungan indeks cephalic dan facial mengacu pada Martin and Saller (1957) sebagai berikut:

Indeks cephalic $=\frac{\text { Lebar Kepala }}{\text { Panjang Kepala }} \times 100$

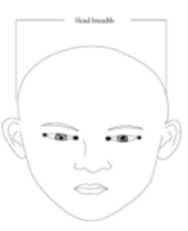

(a)

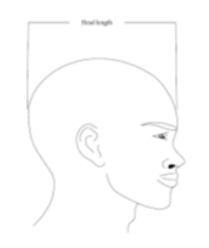

(b)
Gambar 1. Titik pengukuran lebar kepala (a), Titik pengukuran panjang kepala (b) (Akinbami, 2014)

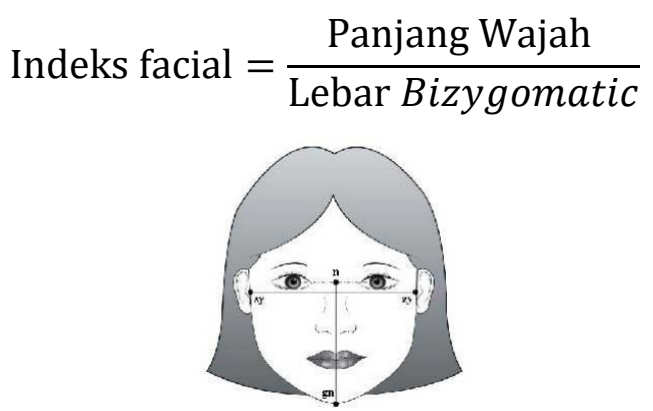

Gambar 8. Lebar wajah (jarak anatara zy kanan sampai dengan zy kiri) dan panjang wajah (jarak antara $\mathrm{n}$ sampai dengan gn) (Yesmin et al., 2014)

\section{HASIL DAN PEMBAHASAN}

Dari penelitian yang telah dilakukan didapatkan hasil seperti tabel berikut.

Tabel 1. Hasil data tipe Kepala pada masyarakata suku Bali di Desa Suro Bali, Kecamatan Ujan Mas, Kabupaten Kepahiang, Provinsi Bengkulu berdasarkan indeks cephalic

\begin{tabular}{lccc}
\hline \multicolumn{1}{c}{ Tipe Bentuk Kepala } & \multicolumn{2}{c}{ Jumlah (\%) } & Jumlah Total (\%) \\
\cline { 2 - 3 } & Laki-laki & Perempuan & $1(1,32)$ \\
\hline Hyperdolichocephalic & $1(3,03)$ & - & $7(9,21)$ \\
Dolichocephalic & $4(12,12)$ & $3(6,98)$ & $14(18,42)$ \\
Mesocephalic & $7(21,21)$ & $7(16,28)$ & $25(32,89)$ \\
Brachycephalic & $13(39,39)$ & $12(27,91)$ & $27(35,53)$ \\
Hyperbrachycephalic & $8(24,24)$ & $19(44,18)$ & $2(2,63)$ \\
Ultrabrachycephalic & - & $2(4,65)$ & $76(100)$ \\
\hline Jumlah Total (\%) & $33(100)$ & $43(100)$ & \\
\hline
\end{tabular}

Tabel 2. Hasil data tipe wajah pada masyarakata suku Bali di Desa Suro Bali, Kecamatan Ujan Mas, Kabupaten Kepahiang Provinsi Bengkulu berdasarkan indeks facial

\begin{tabular}{lccc}
\hline Tipe Wajah & \multicolumn{2}{c}{ Jumlah (\%) } & Jumlah Total (\%) \\
\cline { 2 - 3 } & Laki-laki & Perempuan & $4(5,26)$ \\
\hline Hypereuryprosop & $1(3,03)$ & $3(6,98)$ & $13(17,11)$ \\
Euryprosop & $3(9,09)$ & $10(23,26)$ & $21(27,63)$ \\
Mesoprosop & $4(12,12)$ & $17(39,53)$ & $16(2,05)$ \\
Leptoprosop & $10(30,30)$ & $6(13,95)$ & $22(28,95)$ \\
Hyperleptoprosop & $15(45,45)$ & $7(16,28)$ & $76(100)$ \\
\hline Jumlah Total $(\%)$ & $33(100)$ & $43(100)$ & \\
\hline
\end{tabular}


Dari Tabel 1 dapat diketahui bahwa laki-laki suku Bali kebanyakan mempunyai tipe kepala brachycephalic (39,39\%). Adapun untuk perempuan kebanyakan memiliki kepala hyperbrachycephalic (44,18\%). Dilihat secara keseluruhan tipe kepala masyarakat suku Bali di Desa Suro Bali kebanyakan berupa tipe hyperbrachycephalic $(35,53 \%)$ dan disusul tipe kepala brachycephalic(32,89\%).

Menurut pengklasifikasian ras oleh Koentjaraningrat (1996) suku Bali termasuk ke dalam ras Mongoloid. Amikaramata (2011) mengatakan bahwa ras Mongoloid cenderung memiliki tipe kepala bracycephalic. Terlihat pada Tabel 1 umumnya $(68,24 \%)$ masyarakat suku Bali di Desa Suro Bali memiliki bentuk kepala tipe brachycephalic $(32,89 \%)$ dan tipe hyperbrachicephalic $(35,35 \%)$. Penelitian ini juga sesuai dengan hasil penelitian Lubis (2017) yang membandingkan indeks cephalic dan indeks frontofarietal pada suku Bali dan suku Batak di Kecamatan Tanjung Senang Bandar Lampung. Hasilnya menunjukkan bahwa suku Bali dominan mempunyai tipe kepala hyperbrachycephalic. Di lain pihak tipe kepala hyperdolichocephalic hanya dimiliki $1(1,32 \%)$ orang laki-laki saja. Sedikitnya tipe hyperdolicocephalic sesuai dengan pendapat antropologi Fisher (1953) yang menyatakan bahwa umumnya yang memiliki karakter fisik kepala mengarah pada tipe dolichocephalic adalah kelompok ras Proto Melayu.

Naini et al. (2006) menyatakan bahwa pertumbuhan kepala sangat dipengaruh faktor genetik dan faktor intrinsic yang berasal dari dalam individu manusia itu sendiri seperti nutrisi, kesehatan, derajat aktivitas fisik dan penyakit. Hal-hal dapat menyebabkan perubahan bentuk pada tulang kepala, dimana variasi tersebut berkemungkinan untuk dapat tersebut diturunkan

Berdasarkan Tabel 2 di atas dapat dilihat bahwa penelitian, diketahui laki-laki suku Bali di Desa Suro Bali kebanyakan memiliki tipe wajah hyperleptoprosop
$(45,45 \%)$. Sedangkan untuk perempuan kebanyakan memiliki tipe wajah mesoprosop (39,53\%). Secara keseluruhan tipe wajah orang-orang suku Bali di Desa Suro Bali didominanasi tipe hyperleptoprosop $(28,95)$ dan mesoprosop $(27,63)$.

Penelitian tipe wajah yang telah dilakukan berdasarkan jenis kelamin berbeda dengan hasil penelitian Putra dkk. (2017). Penelitian tersebut menunjukkan hasil bahwa rata-rata tipe wajah suku Bali Desa Panglipuran yaitu pada laki-laki berbentuk ellips atau mesoprosop. Sedangkan pada penelitian ini menunjukkan sebagian besar laki-laki memiliki tipe wajah dan hyperleptoprosop. Selanjutnyamengatakan bahwa umumnya perempuan suku Bali memiliki wajah berbentuk bulat (euryprosop hingga mesoprosop). Ini menunjukkan bahwa penelitian yang dilakukan menguatkan apa yang telah ditemukan oleh Putra dkk. (2017).

Berbagai macam tipe wajah tersebut menurut Martin dan Saller (1957) dipengaruhi oleh bentuk kepala, jenis kelamin, dan usia. Ia juga menyatakan bahwa bagian-bagian lain yang dianggap mempengaruhi wajah adalah tulang pipi, mata, hidung, dagu, mulut, rahang atas maupun rahang bawah, serta dahi.

Frayer and Wolpoff

mengungkapkan bahwa perbedaan antara laki-laki dan perempuan salah satunya terletak pada tulang kerangka terletak pada tulang kerangka dan tulang tengkorak yang bervariasi. Hal tersebut dikenal dengan konsep dimorfisme seksual yang menjadi ciri khas manusia dan organisme lain yang ditandai dengan perubahan dimensi pada jaringan tubuh tertentu yang disebabkan oleh perbedaan jenis kelamin. Perubahan dimensi tersebut mengarah pada bentuk, warna, ukuran maupun lainnya yang berbeda antara laki-laki maupun perempuan. 


\section{SIMPULAN}

Berdasarkan hasil penelitian yang telah dilakukan mengenai morfometri kepala dan wajah pada masyarakat suku Bali di Desa Suro Bali Kecamatan Ujan Mas Kabupaten Kepahiang Provinsi Bengkulu dapat disimpulkan bahwa :

1. Berdasarkan indeks cephalic sebagian besar laki-laki memiliki tipe kepala brachycephalic (39,39\%). Dan perempuan sebagian besar memiliki tipe kepala hyperbrachycephalic (44,18\%).

2. Berdasarkan indeks facial sebagian besar laki-laki memiliki tipe wajah hyperleptoprosop $(45,45 \%)$. Sedangkan perempuan sebagian besar memiliki tipe wajah mesoprosop $(39,53 \%)$.

\section{SARAN}

Berdasarkan penelitian yang telah dilakukan, sebaiknya dilakukan kembali penelitian lanjutan mengenai morfometri kepala dan wajah pada masyarakat suku Bali maupun suku lainnya yang ada di Provinsi Bengkulu dengan metode Landmark agar mendapatkan hasil yang lebih akurat.

\section{UCAPAN TERIMA KASIH}

1. Bapak Dr. Sipriyadi, S.Si., M.Si. dan Bapak Drs. Hery Haryanto, M.Sc. yang telah banyak memberikan masukan, saran dan arahan dalam penyusunan jurnal ini.

2. Bapak Ketut Dana Saputra dan Seluruh Masyarakat Desa Suro Bali yang telah banyak membantu dalam penelitian

3. Randi Wiransyah dan Putu Ratna Wati selaku sekretaris dalam pengumpulan data.

\section{DAFTAR PUSTAKA}

Amikaramata, N. (2011). Hubungan Antara Bentuk Kepala dengan Bentuk Lengkung Gigi dan Bentuk Gigi Insivius Pertama Rahang Atas. Skripsi. Makassar : Fakultas Kedokteran Gigi Universitas Hasanudin,

Artaria, M. D., Glinka, J., dan Koebardianto, T. (2008). Metode Pengukuran Manusia. Surabaya: Airlangga University Press.

Bookstein, F. L. (1991). Morphometric Tools for Landmark Data: Geometry and Biology. New York (US): Cambridge University Press.

Darsana, I. G. P. (1980). Tenganan Pegringsingan: Segi-segi Megalitiknya. Jakarta: Pertemuan Ilmiah Arkeologi.

Glinka, J. (1990). Antropometri dan Antroposkopi, Ed.3. Surabaya: Fisip UNAIR.

Frayer, D. W., dan Wolpoff, M. H. (1985). Sexual Dimorphism. Annual Revew of Anthropology. 14(1): 429-473.

Mantra, I. B. (1991). Landasan Kebudayaan Bali. Denpasar: Yayasan Dharma Sastra.

Martin, R., dan Saller, K. (1957). Lehrbuch der Anthropologie. New York: Gustav Fisher.

Naini, F. B., Moss, J. P., Gill, D. S. (2006). The Enigma of Facial Beauty: Esthetic, Proportions, Deformity, and Controversy. American Journal of Orthodonthics and Dentofacial Orthopedic. 130(1): 277-282.

Putra, A., Wirasiti N. N., Setyawati, I. (2017). Variasi Bentuk Wajah LakiLaki dan Perempuan dari Desa Panglipur Kabupaten Bangli, Provinsi Bali. Jurnal Biologi Udayana. 21(2): 56-63.

Profil Desa Kepahing. (2019). Desa Suro Bali Kecamatan Ujan Mas Kabupaten Kepahiang. Youtube. Kepahiang: Profil Desa KepahiangArtista Studio. https://www.youtube.com/watch?v= 
xUIzDfj4JUI (diakses pada tanggal 15 November 2019)

Widyarini, A. (2009). Variasi wajah dan penderita hipertensi pada wanita di Kampung Naga. Skripsi. Bogor (ID): Institut Pertanian Bogor. 